\title{
Ober eine neue Indolreaktion.
}

\author{
Von \\ Oskar Baudisch.
}
(Mitteilung aus dem k. k. serotherapeut. Institut in Wien, Direktor k. k. Hofrat Prof. Dr. Rich. Paltauf.)
- (Der Redaktion zugegangen am 27. April 1915.)

Früher spielte die «Cholerarotreaktion > in der Diagnostik eine bedeutende Rolle.

Mit Cholerarotreaktion bezeichnete man jene burgunderweinrote Färbung, die eintritt, wenn man geringe Mengen konzentrierter chemisch reiner Schwefelsäure oder Salzsäure zu Bouillon- oder Peptonwasserkulturen hinzufügt. Nach Brieger, Dunham und Salkowski kommt die rote Färbung dadurch zustande, daß in der Cholerakultur sowohl Indol als auch Nitrit gebildet wird, welche beiden Stoffe sich durch die Einwirkung starker Mineralsäuren zu roten Nitrosoindol verbinden.

Seitdem man gefunden hat, daß viele choleraähnliche Vibrionen und verschiedene andere nicht pathogene Darmbakterien ebenfalls diese Reaktion geben, fällt ihr in der Diagnostik nur insofern eine Rolle $\mathrm{zu}$, daß ein negativer Ausfall der Cholerarotreaktion beweist, daß die verdächtige Kultur keine Cholerakultur ist. Die frühere Cholerarotreaktion verlor daher immer mehr ihre spezifische Bedeutung, und sie gehört heute einfach in die Reihe der verschiedenen Indolreaktionen. Dazu gehören heute die eben erwähnte alte Salkowskische, die Ehrlichsche Para-Dimethylamidobenzaldehydreaktion, ${ }^{1}$ ) die Reaktion von $\mathrm{Morelli}^{2}$ ) und ferner die Nitroprussidnatriumreaktion. ${ }^{3}$ )

1) G. f. Bakt. I. Org., Bd. 40, S. 129.

2) C. f. Bakt. I. Org., Bd. 50, S. 433 .

3) Biochem. Zeitschr., Bd. 56, S. 82. 
Bandet.1) welcher alle die verschiedenen Indolreaktionen bei Proteusbazillen einer vergleichenden kritischen Prüfung unterzogen hat, fand, daß das p-Dimethylamidobenzaldehydreagens bei der praktischen qualitativen Indolbestimmung wegen seiner Empfindlichkeit besonders zu empfehlen ist. Auch Hugo Zipfel') hatte schon früher die EhrlichBöhmesche Reaktion als die empfindlichste Indolreaktion bezeichnet.

Nach Ehrlich-Böhme werden zu $10 \mathrm{ccm}$ flüssiger Kultur $5 \mathrm{ccm}$ Lösung a und dann $5 \mathrm{ccm}$ Lösung b hinzugegeben und geschüttelt. (Lös. a : p-Dimethylamidobenzaldehyd $4+96 \%$ Alkohol $380+$ konz. HCl 80 ; Lös. b: gesättigte wässerige Lösung von Kaliumpersulfat $\left(\mathrm{K}_{2} \mathrm{~S}_{2} \mathrm{O}_{8}\right)$.

Die Ehrlichsche Reaktion ist ohne Zweifel heute die empfindlichste und beste Indolreaktion, jedoch läßt sie sich nicht speziell als Cholerawahrscheinlichkeitsreaktion verwerten. Man braucht zu ibrer Ausführung eine flüssige Kultur, ferner jene eben erwähnten bestimmt zusammengesetzten kostspieligen Lösungen, was besonders in Feldlaboratorien schwer zu beschaffen ist.

In dieser Arbeit wird der Versuch gemacht, die neue Indolreaktion gleichzeitig als Wahrscheinlichkeitsreaktion auf Choleravibrionen zu verwerten, jedoch werden erst spätere, mit einer großen Anzahl von Cholerastühlen ausgeführte Versuche Aufschluß geben, ob diese Indolreaktion wirklich in diesem Sinne zu gebrauchen ist.

Der Choleravibrio baut sein Körpereiweiß bedeutend rascher im Sinne des Tryptophanstoffwechsels $a b$ als andere Bakterien, und so gelang es schon nach 8-16 stündigem Wachstum der Kulturen, Indol in denselben nachzuweisen, was bei den bisher untersuchten anderen indolbildenden Bakterien nicht der Fall war.

Eine Wahrscheinlichkeitsreaktion auf Cholera müßte sich deshalb darauf stützen, an einzelnen Kolonien oder Koloniengruppen, von auf Agarplatten gewachsenen Kulturen, schon

3) Fol. microbiol., Jg. 2 (1914).

') Zentr. f. Bakt. I., Bd. 67, S. 572. 
nach 8-16 Stunden entweder eine positive oder eine negative Indolreaktion nachzuweisen. Bisher fehlte es an einer diesbezüglichen, praktisch verwendbaren Indolreaktion.

Mit Hilfe von Nitromethan ist es mir gelungen, eine Indolreaktion auszuarbeiten, die an Empfindlichkeit der Ehrlichschen Reaktion nicht nachsteht. Dabei ist diese Reaktion so einfach ausführbar, daß auch ihrer Verwendung in Feldlaboratorien nichts im Wege steht. Das Nitromethan kann man entweder schon bei der Bereitung von Nähragar diesem zusetzen; es braucht nur wenige Tropfen Nitromethan auf große Agarmengen. Hat man schon so vorbereiteten Agar, so gehört zu der Reaktion nichts anderes als Kali oder Natronlauge (Soda, Ammoniak) und eine Mineralsäure. Man kann aber auch das Nitromethan anstatt der Agarlösung, der verdünnten ca. 10-20\% igen Lauge hinzusetzen, der Effekt bleibt der gleiche.

Ausführung der Reaktion: Man beschickt erstarrte Agarplatten durch Oberflächenaussaat mit dem Untersuchungsmaterial, um isolierte Kulturen $\mathrm{zu}$ erhalten. Bei Prüfung eines verdächtigen Stuhles wird es vielleicht am meisten zu empfehlen sein, zuerst Dieudonnéplatten zu beschicken und erst von diesen verdächtigen Cholerakulturen weitere Agarplatten zu streichen. Nach 8-16 stündigem Wachstum im Brutschrank umgrenzt man mit der Platinöse oder besser mit einem Platinspatel die zu untersuchende Kolonie oder besser Koloniengruppe mit dem darunterliegenden Agar, hebt dann die Kolonie mit dem Agarbett heraus und gibt das Ganze in ein Reagensglas. Enthielt der Agar bereits Nitromethan - wie ich das vorher dargelegt habe -, so braucht man in das Reagensglas nur verdünnte Kalilauge zu geben und aufzukochen. Die heiße Lösung kühlt man am Wasserhahn etwas ab, gibt ca. $1 \mathrm{ccm}$ Amylalkohol hinzu, schüttelt gut durch und nun fügt man konzentrierte Salzsäure im Überschuß unter abermaligem Schütteln bei. Damit sich der Amylalkohol gut absetzt, erwärmt man das Ganze nochmals fast bis zun Kochen. Der abgetrennte Amylalkohol ist, wenn die Kolonien auch nur äußerst geringe Mengen Indol produziert hatten, 
rot oder rosa gefärbt und zwar wechselt die Intensität der Färbung je nach dem Indolgehalt. Enthielt der Agar kein Nitromethan, so gibt man einige Tropfen von diesem Reagens zu der verdünnten Lauge, die dann in dieser Form für die Indolreaktion immer bereit ist.

Ich hoffe, daß diese Indolreaktion als Wahrscheinlichkeitsreaktion auf Choleravibrionen auch in Feldlaboratorien eine praktische Bedeutung finden wird. Ich selbst werde mich mit der weiteren praktischen Ausarbeitung der neuen Reaktion befassen, bin jedoch dankbar, wenn auch andere Fachkollegen ihre Brauchbarkeit für einen raschen, spezifischen Choleranachweis erproben. 